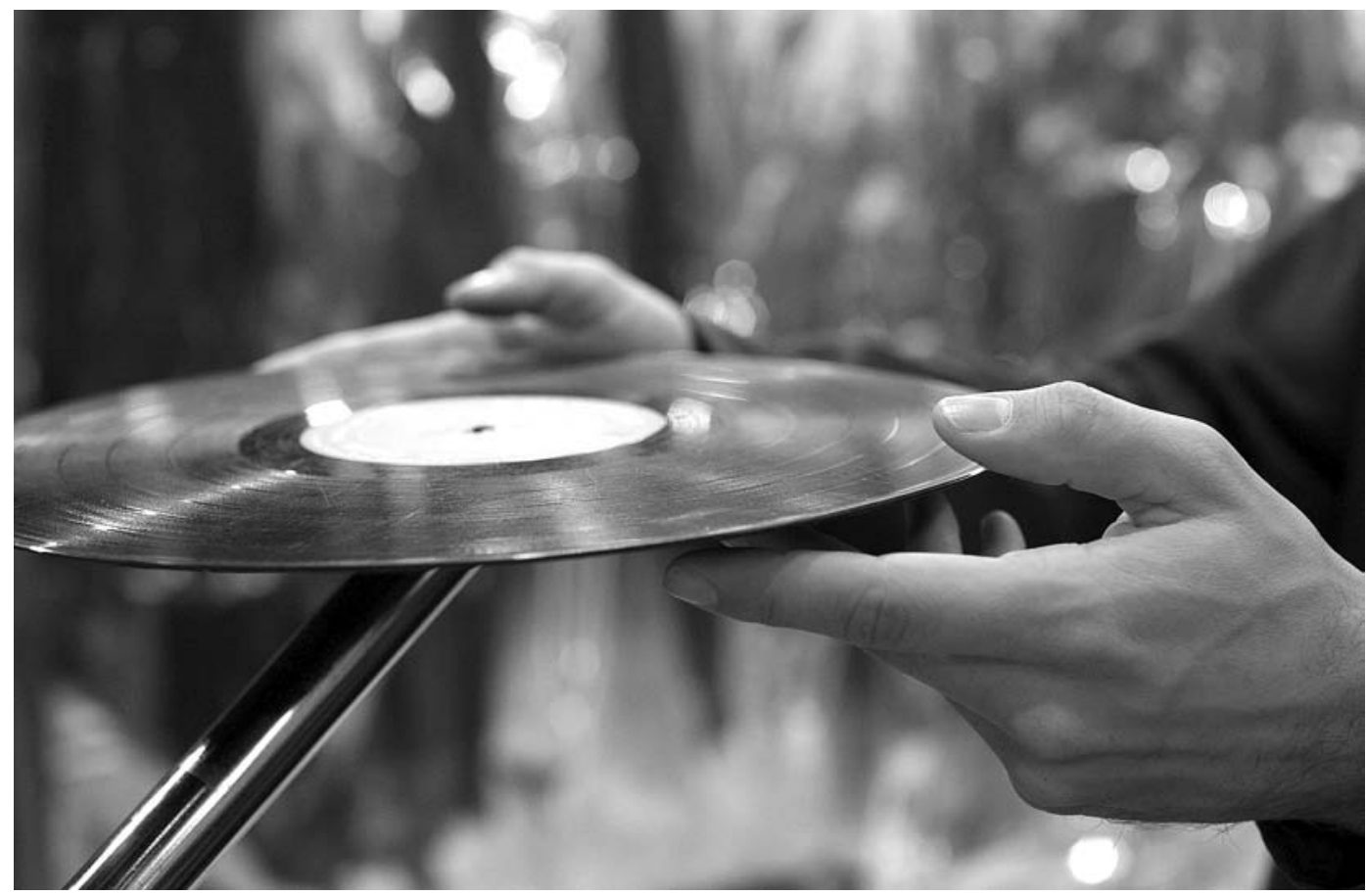

Push and Pull: A Furniture Comedy for Hans Hofman, dir. Allan Kaprow, 1963/2007, fot. Paula Court [cortesia de PERFORMA e Creative Time].

\title{
Refazer o irrepetível
}

\section{Ana Pais}

A performance pode afectar a nossa vida retrospectivamente.

Marina Abramovic

Em Outubro de 2007, Nova lorque recebeu a segunda edição da bienal PERFORMA. Comissariada por RoseLee Goldberg, incontornável historiadora da performance, esta bienal assume-se como um festival de artes visuais. Por isso, a maior parte das obras encomendadas pela PERFORMA (10 em 95 trabalhos apresentados) resultaram de convites dirigidos a jovens artistas plásticos, com pouca ou nenhuma produção na área da performance. Ao italiano Francesco Vezzoli - com obras já expostas na Fundação de Serralves - coube, por exemplo, a ultra elegante abertura do evento, no átrio do Museu Guggenheim.

Na linha de cáusticos e reflexivos trabalhos anteriores sobre a fama, as celebridades e a própria arte, Vezzoli adaptou a peça de Pirandello Para cada um a sua verdade (Cosi è (se vi pare)), numa leitura encenada com estrelas de Hollywood: Natalie Portman, Dianne Wiest, Peter Sarsgaard e Cate Blanchett, entre outros. E surpreendeu pela ironia com que questionou as matérias do efémero e da mediação tecnológica, dos múltiplos pontos de vista e da relação palco/plateia, seguramente, nem por todos apreciada. Os actores contracenam, sentados a uma mesa exígua e fechados numa alta estrutura metálica. Voltados de frente uns para os outros, quase todos são filmados em close-up e estas imagens são projectadas simultaneamente num ecrã, mas apenas num pequeno auditório na cave do museu. Este inteligente ardil é responsável pela situação mais intrigante do espectáculo pois cria uma curiosa fricção entre as duas versões perceptivas do público VIP no átrio - que não pode ouvir nem ver em boas condições os actores - e de todos os que ai não conseguiram lugar mas vêem e ouvem tudo e que assistem no auditório à vídeo-performance. Qual delas a verdadeira, qual delas a falsa.

Parece evidente, na aposta de Goldberg, a determinação em estimular estratégias de interdisciplinaridade, tomando a figura do curador enquanto facilitador de oportunidades e promotor de caminhos de pesquisa. Na medida em que Allan Kaprow, o pintor/escultor que atravessa as fronteiras das artes para inventar o happening, foi um dos grandes fundadores do hibridismo na performance, e a inclusão da recriação de várias obras suas neste festival, por coincidência, no ano seguinte ao da sua morte, resulta numa óbvia e emocionante homenagem.

Sobretudo para quem há muito se interessa pelo seu legado estético e teórico, poder assistir ao vivo a três obras essenciais de Kaprow constituia uma oportunidade única de "reviver" um passado nunca vivido e, ainda por cima, acrescido da consciência retrospectiva da sua importância artística para o século XX. Na Cooper Union Square, foi reconstruido Fluids, um happening de 1967: um paralelepípedo constituido por blocos de gelo que durante três dias derreteram à mercê dos olhares curiosos dos transeuntes; no espaço da Creative Time, em Chelsea, bairro das chiquérrimas vernissages e galerias, foi recriado Push and Pull: a furniture comedy for Hans Hoffman, um environment/happening de 1963, onde o visitante era convidado a deslocar a mobilia e os objectos da sala, fazendo com que a obra estivesse em constante mudança;
Epigrafe no site da PERFORMA 07: http://07.performaarts.org

Ana Pais

é professora da Escola Superior de Teatro e Cinema e crítica do semanário Sol. 


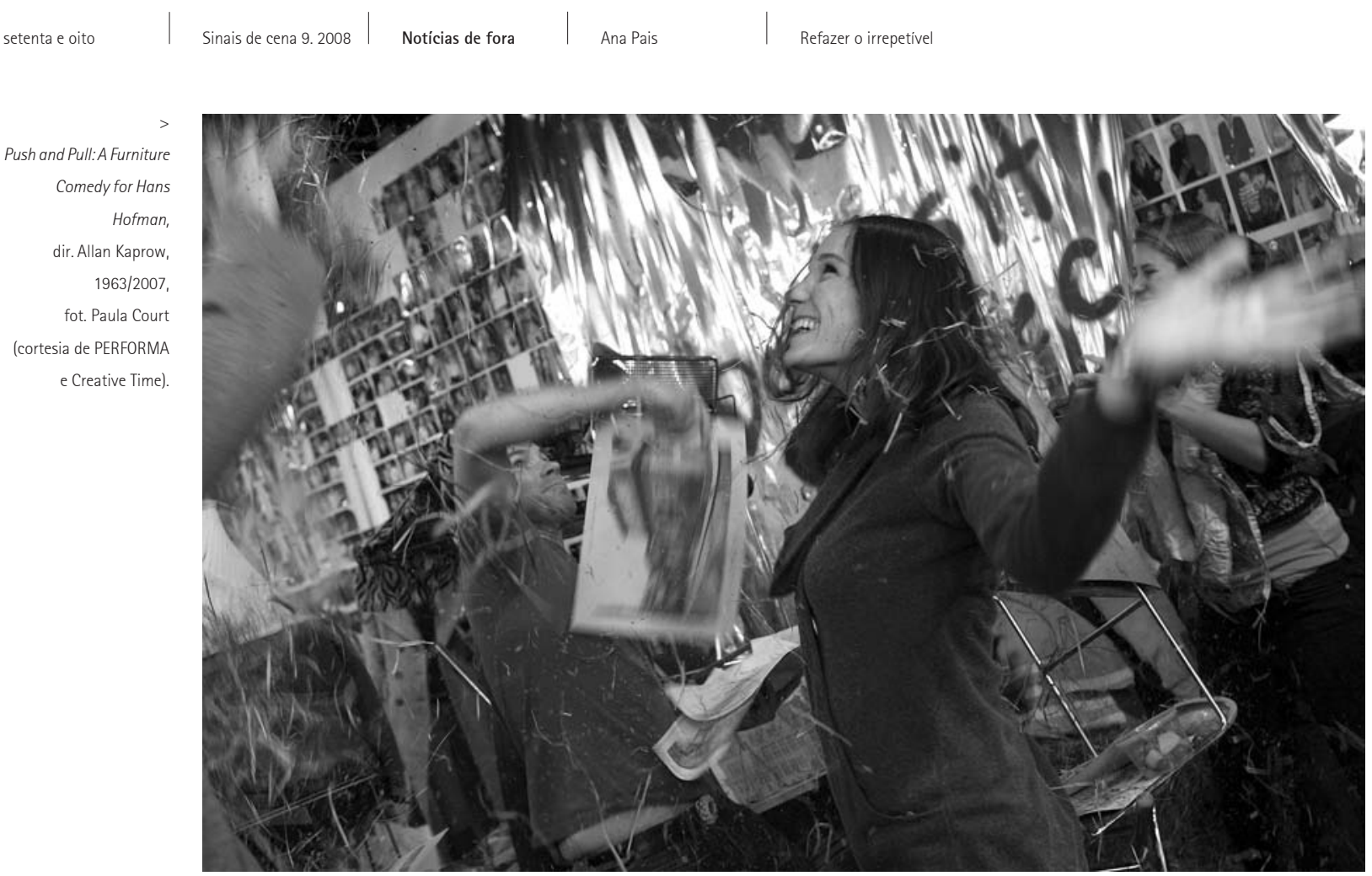

no Deitch Studios, em Long Island City (um amplo pavilhão junto ao rio que só pela vista deslumbrante sobre Manhattan valia a pena visitar), foi reinventado o happening mais marcante da História, 18 Happenings in 6 Parts (Re-doing), acontecimento levantado a partir dos abundantes e detalhados apontamentos de Kaprow (notas e desenhos de trabalho, textos, guiões sonoros e de movimento) pela mão de André Lepecki (crítico, dramaturgista e professor na Universidade de Nova lorque). Este último, originalmente integrado na grande exposição retrospectiva Art as Life, dedicada a Kaprow e promovida pela Haus der Kunst, em Munique (2006), é o happening sobre o qual me alongarei neste artigo.

Sabendo que Kaprow sempre defendera a irrepetibilidade dos happenings, esta parece-nos uma ideia quase chocante. No entanto, talvez por já se encontrar doente quando as curadoras procuraram dialogar com ele para conceber a exposição e solicitar os direitos das obras, o "criador-controlador" entendeu ser o momento para abandonar os seus happenings à reinvenção de outros, dando assim início a uma nova fase na sua obra e na história da performance.

Apresentado pela primeira vez na Reuben Gallery de Nova lorque, em 1959, 18 Happenings in 6 Parts constituiu um momento de charneira na experimentação dos limites das disciplinas artísticas. Organizando o espaço em três salas, Kaprow estruturou ao pormenor uma composição de eventos não-narrativos e "amatriciais" (segundo a terminologia proposta por M. Kirby (1968)), i.e., sem qualquer referência a um universo ficcional (espaço, tempo ou personagem), realizada por seis performers (entre eles o próprio Kaprow) e artistas convidados como Red Grooms ou Robert Rauschenberg. Devendo trocar de lugar em cada "parte" do evento indicada, o público deveria seguir a folha de instruções rigorosas distribuida à entrada da galeria, tendo uma visão necessariamente parcial das acções que decorriam simultaneamente nas outras salas. Os happenings propriamente ditos variavam entre pequenas acções ou discursos, projecção de diapositivos, espremer 12 metades de laranjas e beber o sumo a seguir ou movimentos coreográficos sendo que, para assinalar cada "parte", soava uma campainha.

Nesta nova apresentação, 18 Happenings in 6 Parts surge-nos como um objecto estranho, viajando numa cápsula preservada e inscrita na História. São as expectativas, quer desejássemos entrar numa máquina do tempo quer preferissemos testemunhar as diferenças na versão de André Lepecki, que mais povoam o acontecimento. Embora a perspectiva arqueológica - e impossivel - de representar o acontecimento original estivesse fora da equação, é dificil não atribuir a este gesto um carácter documental, ou, pelo menos, tributário. No acrescento parentético ao título da obra (Re-doing), encontramos reforçada a ideia do fazer de novo como fundamento deste evento, não escondendo a sua fértil ambiguidade: fazer de novo como repetição do mesmo, procurando uma fidelidade às regras de Kaprow, ou refazer no sentido de reflectir sobre uma partitura e, portanto, acrescentar-Ihe algo, inevitável, de resto, se considerarmos que a arte é sempre um repensar e um refazer de alguma coisa? É, justamente, nesta duplicidade que o (Re-doing) de 18 Happenings in 6 Parts procura delimitar um espaço.

$\mathrm{Na}$ folha de sala, André Lepecki assinala a sua posição: a "fidelidade absoluta" do seu projecto vai para o "poder contido nas notas de Kaprow", o que significa "testar os limites da obra", não apenas aferindo a possibilidade de seguir a sua prescrição rigorosa e dogmática, como também questionando o que muda essa acção na obra e na performance, passados cinquenta anos. A questão de fundo prende-se, como seria de esperar, com a temporalidade e a actualidade tanto da obra ao vivo quanto das notas e desenhos do autor, que, como assinala o "refazedor", detêm elas mesmas um potencial performativo, de materialização, que se consubstancia no papel.

No sentido em que hoje a experiência de 18

Happenings in 6 Parts dificilmente pode ignorar o seu peso artistico e cultural, refazer este happening leva-nos 


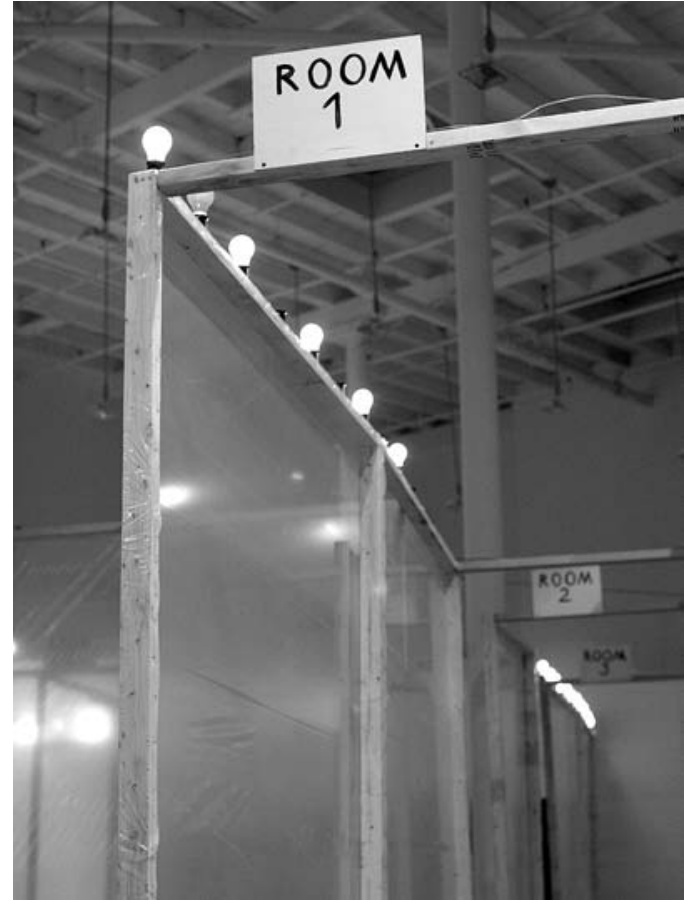

a repensar três aspectos cruciais em Kaprow: a experiência do espectador, bem como o estatuto do artista e da obra.

Um dos factores que conduziu Allan Kaprow a explorar os limites das artes plásticas através da performatividade foi o ter constatado que os seus environments se transformavam quando um visitante entrava em cena. Em nada devedor do acaso, o happening terá no seu espectador a sua mais intensa variável, sendo, por isso, o elemento que mais foge ao seu controlo autoral, descrito em partituras e notas. Inspirado na força agenciadora patente nestas notas, o (Re-doing) de André Lepecki oferece uma dupla experiência: a do momento-vivido (tal como desejou Kaprow) e a do momento-historicamenteinformado (tal como a potenciou Lepecki), colocando o público numa posição de privilegiado viajante entre-

tempos. Sabendo que Kaprow escolhera o termo happening de modo a contornar as nomenclaturas da arte - sem sucesso, como sabemos - e que viria a defender o conceito de "arte como vida" e de "não-artista", numa estratégia de redefinição democratizante do estatuto da obra e do autor, obviamente, parte dessa redefinição antecipava a hipótese do presente (Re-doing), a hipótese de os seus guiões prescritivos serem relidos e refeitos por outrem. Levanta-se, portanto, a questão da autoria - quem assina este (Re-doing)? Quem é o verdadeiro autor do happening a que assistimos hoje? De novo, a resposta só pode ser encontrada na ambiguidade do título que, por sua vez, se prende com a relação entre a partitura escrita por Kaprow e a possibilidade de um evento, numa temporalidade múltipla. Considerando o desafio que as notas de Kaprow Ihe ofereceram como uma oportunidade para repensar a relação da performance com a sua própria temporalidade, André Lepecki destaca na efemeridade da performance uma condição de regresso e repetição a que a escrita enquanto potenciadora de actos porvir se permite e que, paradoxalmente, o texto dramático, ainda que no seu quadro matricial específico, exige.

Da minha experiência, retiro o intenso prazer de assistir a um pensamento em movimento, a uma rememoração

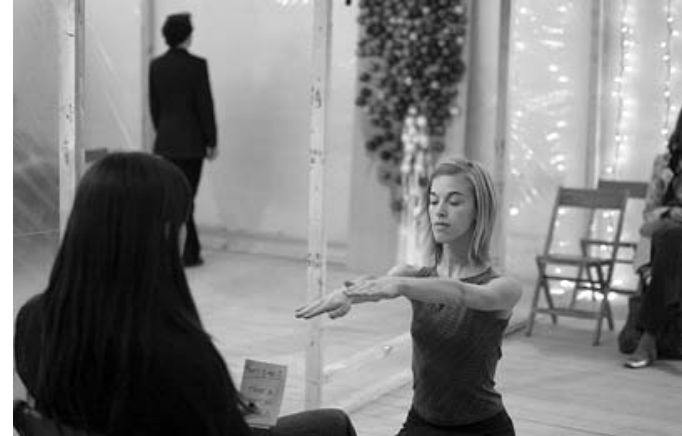

18 Happenings in 6 Parts (Re-doing),

de Allan Kaprow, 2007 (> Marc Etlin e Sebastian CalderónBentin;

$\checkmark$ Noémie Solomon), fot. Paula Court (cortesia de PERFORMA Allan Kaprow Estate e Hauser \& Wirth Zurich

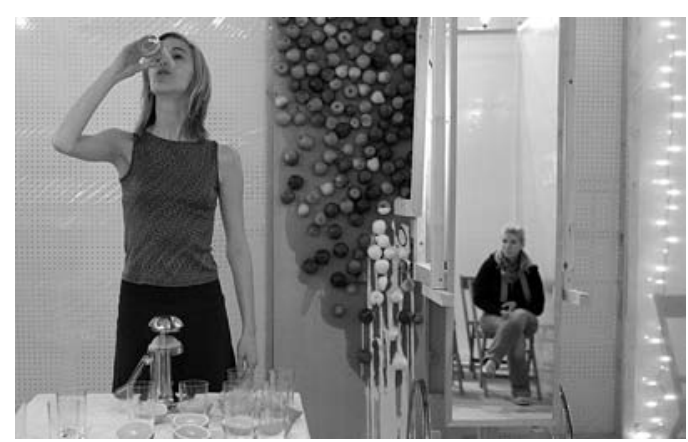

( Londres) rigorosa e atenta de um evento extraordinário na história das artes do século XX, saido do génio de um dos seus mais brilhantes e completos criadores. A sensação de entrar num espaço que reproduzia as dimensões e a aparência plástica semelhante às imagens fotográficas existentes do happening original, de seguir na folha de sala as indicações ao público, de reconhecer os objectos cénicos e as pequenas acções que tantas vezes lera apenas no papel, de ouvir os registos sonoros que, de tão pouco musicados, me pareceram gritantemente de uma electrónica contemporânea, foi rica e indiscutivelmente valiosa. Curiosamente, o que mais me surpreendeu foi sentir o seu tempo peculiar, dar-me conta da sua passagem e da pertinência dos vários momentos, em particular, dos de interregno (os intervalos) e como estes dialogam com os happenings propriamente ditos.

Sobretudo nos dois intervalos de 15 minutos, e desde que nos detivéssemos um pouco a observar, a duração instalou-se como uma inegável e irónica passagem para o acaso: por vezes mais do que durante as acções previstas e ensaiadas, os intervalos, igualmente previstos mas impossiveis de ensaiar, introduziam no hapenning uma camada de quotidiano constituída por palavras, gestos e movimentos da total responsabilidade do público. Nas acções espontâneas dos espectadores incidia, pois, um interesse semiológico para os outros espectadores, uma vez enquadradas num espaço e num tempo artísticos, que só é possivel detectar na experiência do momento, não na leitura. Podemos dizer que o (Re-doing) afecta o happening de 1959, criando um plano de intersecção entre o momento original e as apresentações de 2006/7, cuja tangente são as notas escritas. Refazendo igualmente a frase de Marina Abramovic em epigrafe: a performance afecta, retroactivamente, não só a nossa vida como também a performance irrepetivel.

\section{Referência bibliográfica}

KIRBY, Michael (1968), Happenings, New York, E. P. Dutton. 